\section{Molecular and Cellular Biology}

The effector domain of Rab6, plus a highly hydrophobic C terminus, is required for Golgi apparatus localization.

F Beranger, H Paterson, S Powers, J de Gunzburg and J F Hancock

Mol. Cell. Biol. 1994, 14(1):744. DOI: 10.1128/MCB.14.1.744.

Updated information and services can be found at: http://mcb.asm.org/content/14/1/744

These include:

CONTENT ALERTS

Receive: RSS Feeds, eTOCs, free email alerts (when new articles cite this article), more» 


\title{
The Effector Domain of Rab6, Plus a Highly Hydrophobic C Terminus, Is Required for Golgi Apparatus Localization
}

\author{
FLORENCE BERANGER, ${ }^{1}$ HUGH PATERSON,${ }^{2}$ SCOTT POWERS, ${ }^{3}$ JEAN DE GUNZBURG, ${ }^{1}$ \\ AND JOHN F. HANCOCK ${ }^{3 *}$ \\ INSERM Unité 248, Faculté de Médecine Lariboisière-St. Louis, 75010 Paris, France ${ }^{1}$; \\ Institute of Cancer Research, Chester Beatty Laboratories, London SW3, England2; \\ and ONYX Pharmaceuticals, Richmond, California $94806^{3}$
}

Received 11 June 1993/Returned for modification 29 July 1993/Accepted 4 October 1993

\begin{abstract}
C-terminal lipid modifications are essential for the interaction of Ras-related proteins with membranes. While all Ras proteins are farnesylated and some palmitoylated, the majority of other Ras-related proteins are geranylgeranylated. One such protein, Rab6, is associated with the Golgi apparatus and has a C-terminal CXC motif that is geranylgeranylated on both cysteines. We show here that farnesylation alone cannot substitute for geranylgeranylation in targeting Rab6 to the Golgi apparatus and that whereas Ras proteins that are farnesylated and palmitoylated are targeted to the plasma membrane, mutant Rab proteins that are both farnesylated and palmitoylated associate with the Golgi apparatus. Using chimeric Ras-Rab proteins, we find that there are sequences in the N-terminal 71 amino acids of Rab6 which are required for Golgi complex localization and show that these sequences comprise or include the efiector domain. The C-terminal hypervariable domain is not essential for the Golgi complex targeting of Rab6 but is required to prevent prenylated and palmitoylated Rab6 from localizing to the plasma membrane. Functional analysis of these mutant Rab6 proteins in Saccharomyces cerevisiae shows that wild-type Rab6 and C-terminal mutant Rab6 proteins which localize to the Golgi apparatus in mammalian cells can complement the temperature-sensitive phenotype of ypt6 null mutants. Interestingly, therefore, the C-terminal hypervariable domain of Rab6 is not required for this protein to function in $S$. cerevisiae.
\end{abstract}

Ras-related proteins are 21- to $25-\mathrm{kDa}$ proteins which bind guanine nucleotides and have GTPase activity. On the basis of their sequence homology, they can be divided into three main subfamilies: Ras, Rho, and Rab (13). All operate as molecular switches by interacting with different sets of proteins in the inactive GDP- or active GTP-bound state (reviewed in reference 8). Ras-related proteins are involved in regulating a wide range of cellular processes, including cell proliferation, differentiation, intracellular trafficking $(7$, $24)$, membrane ruffling, and assembly of actin stress fibers $(43,44)$. Although these proteins serve very diverse functions, their ability to associate with cell membranes is a fundamental requirement for biological activity (review in reference 20) such that mutations in Ras, Rho, and Rab proteins which block membrane localization also render these proteins biologically inactive $(2,21,40,49,51)$.

The mechanism of attachment of Ras proteins to the inner surface of the plasma membrane provides a model for the membrane targeting of other Ras-related proteins. The $\mathrm{C}$ terminus of Ras terminates in a CAAX motif $(C=$ cysteine, $\mathrm{A}=$ aliphatic amino acid, $\mathrm{X}=$ any amino acid) which undergoes farnesylation of the cysteine residue $(12,28)$, proteolysis by an endopeptidase to remove the AAX amino acids $(19,23)$, and carboxyl-methyl esterification of the cysteine $(16,23)$. Although these modifications render the $\mathrm{C}$ terminus of the protein hydrophobic and thereby facilitate membrane association, additional protein sequences in the adjacent C-terminal hypervariable region are required to target Ras proteins to the plasma membrane. This second

\footnotetext{
* Corresponding author. Mailing address: ONYX Pharmaceuticals, 3031 Research Dr., Richmond, CA 94806. Phone: (510) 222 9700. Fax: (510) 2229758.
}

signal is a polylysine domain in K-Ras and cysteine palmitoylation sites in the $\mathrm{H}$ - and $\mathrm{N}$-Ras proteins. This combination of CAAX motif plus a second signal is also sufficient to target cytosolic heterologous proteins, such as protein $A(25)$ or p120 GTPase-activating protein (GAP) (34), to the plasma membrane.

It is interesting to note that while Ras proteins are farnesylated, the majority of other Ras-related proteins are geranylgeranylated (reviewed in reference 29). Alkylation with $\mathrm{C}_{20}$ geranylgeranyl occurs on proteins with three different C-terminal motifs; CAAX motifs, where $\mathrm{X}$ is a leucine or a phenylalanine, are prenylated by geranylgeranyltransferase I (GGTase I) $(11,41,47)$, and CC and CXC motifs, which are found at the $\mathrm{C}$ termini of Rab proteins, are prenylated by GGTase II, also known as Rab geranylgeranyltransferase $(32,45,46)$. Following geranylgeranylation, CAAL/F motifs are AAX proteolysed and methylated. The CXC motif is geranylgeranylated on both cysteines and is also methylated $(18,42)$. The stoichiometry of geranylgeranylation of the CC motif is less certain $(20,36,38,50)$. However, this motif is not methylated $(42,50)$. It is reasonable to speculate that there is a single $C_{20}$ geranylgeranyl group attached to the upstream cysteine, since a carboxy-terminal geranygeranyl cysteine would be a substrate for methylation. The biological significance of these different stoichiometries and different methylation statuses is not known. The farnesyltransferase and GGTase I prenylate CAAX or CAAL tetrapeptides in vitro, while the recognition sequence for Rab GGTase II is more complex (35) and may involve Rab sequences remote from the CC and CXC motifs.

Rab proteins are attached to different intracellular membranes and are involved in endocytosis and secretion $(9,48)$. The targeting of Rab proteins to specific subcellular locations is determined in part by their C-terminal sequences 
(14), but whether these sequences are sufficient to target heterologous proteins to the same locations is unclear, and the role played by geranylgeranylation in Rab localization has not been investigated. An interesting question is whether $\mathrm{C}_{15}$ (farnesol) and $\mathrm{C}_{20}$ (geranylgeranyl) moieties are interchangeable for Rab proteins. Such analysis of Ras has yielded some interesting observations. First, Ras proteins with an $\mathrm{X} \rightarrow \mathrm{L}$ mutation in the CAAX box undergo geranylgeranylation but are still localized to the plasma membrane. However, if the polybasic domain or palmitoylation site is removed, these geranylgeranylated Ras proteins are associated with intracellular membranes and not the plasma membrane (25). Geranylgeranylated oncogenic Ras proteins are transforming irrespective of their subcellular localization (25), but low-level expression of plasma membrane-localized geranylgeranylated wild-type Ras is growth inhibitory (17).

The Rab6 protein is localized in the medial and trans cisternae of the Golgi complex (22). The C-terminal CSC sequence predicts prenylation with two geranylgeranyl groups followed by methylation. We have constructed Rab6 proteins with a set of alternative C-terminal motifs (CC, CCIL, CKCCIL, CVLS, and CKCVLS) to direct all known combinations of C-terminal lipid modifications. Our results show that farnesylation alone cannot substitute for geranylgeranylation to localize Rab6 to the Golgi complex, demonstrating a significant functional difference between these isoprenoids. However, a combination of farnesylation plus palmitoylation, which localizes heterologous proteins to the plasma membrane, localized Rab6 to the Golgi complex. We conclude that the Rab6 protein contains sequences which can override the plasma membrane-targeting function of this lipid combination and show that while these overriding sequences are contained within the C-terminal hypervariable domain of the protein, the Golgi-targeting sequence is not. A functional analysis of mutant Rab6 proteins in Saccharomyces cerevisiae shows that suppression of the $y p t 6^{-}$ phenotype correlates with Golgi localization in mammalian cells and that the C-terminal hypervariable domain of Rab6 is not required for function in yeast cells.

\section{MATERIALS AND METHODS}

Constructs. The C-terminal sequences used to construct the mutant Rab6 proteins were synthesized by PCR, using as the templates H-ras CCIL and H-ras CAIL mutant cDNAs, which have CAAX motifs that direct geranylgeranylation (described in reference 25), wild-type H-ras cDNA, and wild-type rab6 cDNA (52). The PCR primers included novel restriction sites for cloning that did not alter the coding sequence. The PCR products were cloned into pGEM $9 \mathrm{Zf}(-)$ (Promega) for sequencing and subsequently cloned in frame into the coding sequence of Rab6 in the eukaryotic expression vector $\mathrm{pEXV} 3$. Other mutations were introduced into appropriate templates by oligonucleotide-directed mutagenesis, using a mutagenesis kit (Amersham International, Amersham, England). The Myc epitope, cloned into the bacterial expression vector ptrp-tag, was obtained from Alan Hall (Chester Beatty Laboratories, London, England). The coding sequence for MEQKLISEEDL was removed, and by using PCR, a Kozak consensus sequence was introduced at the $5^{\prime}$ end to optimize eukaryotic expression. The modified tag was cloned in frame onto the $\mathrm{N}$ terminus of rab6 and resequenced, and this new Myc-tagged rab6 cDNA was used to make other Myc-tagged constructs by simple recombination.

In vitro translation and isoprenoid analysis. Mutant and wild-type rab6 cDNAs were cloned into pGEM vectors (Promega), and mRNA was prepared by in vitro transcription. Nuclease-treated rabbit reticulocyte lysate was obtained from Promega, and translations were performed according to the manufacturer's instructions. Reactions were performed at $30^{\circ} \mathrm{C}$ for $90 \mathrm{~min}$, using $2 \mu \mathrm{g}$ of uncapped RNA in a reaction volume of $50 \mu$ l with $50 \mu \mathrm{Ci}$ of $\mathrm{R}\left[5-{ }^{3} \mathrm{H}\right] \mathrm{meval}-$ onic acid (NET 716; NEN). The whole lysate was partitioned in Triton X-114, and the detergent-partitioning fraction was immunoprecipitated with anti-Rab6 antibodies. Following sodium dodecyl sulfate (SDS)-polyacrylamide gel electrophoresis (PAGE), the gel was soaked in Enlightening (NEN) and autoradiographed. The labelled bands were digested with pronase from gel slices that had been excised using the autoradiogram as a guide. Labelled peptides were cleaved with methyl iodide by the method of Casey et al. (12) and analyzed by high-pressure liquid chromatography as previously described (42).

COS cell expression and Triton X-114 partitioning. COS1 cells were electroporated by a method based on that of Chu et al. (15). Cells were harvested $72 \mathrm{~h}$ after transfection and fractionated as described previously (10) except that membranes were pelleted at $120,000 \times g$ for $30 \mathrm{~min}$. For the pulse-chase experiments, cells were incubated in methionine-free Dulbecco modified Eagle medium (DMEM) for 1 $\mathrm{h}$ before being metabolically labelled for $10 \mathrm{~min}$ with $0.3 \mathrm{mCi}$ of Expres $\left({ }^{35} \mathrm{~S}\right.$ ) labelling mix (NEG072; NEN) per $\mathrm{ml}$ in methionine-free DMEM. Labelled cells were lysed immediately or chased for 6 or $24 \mathrm{~h}$ with unlabelled medium. Alternatively, cells were labelled with $1 \mathrm{mCi}$ of $\left[{ }^{3} \mathrm{H}\right]$ palmitic acid (TRK760; Amersham) per $\mathrm{ml}$ for $4 \mathrm{~h}$ in DMEM containing $5 \mathrm{mM}$ pyruvate (39). Cell lysates were prepared in $1 \%$ Triton X-114 containing a cocktail of protease inhibitors (leupeptin, soy bean trypsin inhibitor, and aprotinin), incubated on ice for $10 \mathrm{~min}$, and centrifuged at $4^{\circ} \mathrm{C}$ to remove insoluble debris. The lysates were separated into aqueous and detergent phases by being warmed to $37^{\circ} \mathrm{C}$ for $2 \mathrm{~min}$ and then microcentrifuged for $2 \mathrm{~min}(6,23)$. $\left[{ }^{3} \mathrm{H}\right]$ palmitic acidlabelled samples were not phase separated. Aqueous and detergent-enriched phases were either immunoprecipitated with anti-Rab6 antibodies if radiolabelled or trichloroacetic acid precipitated if not. Immunoprecipitations were carried out as described previously (22), boiled in Laemmli sample buffer, resolved by SDS-PAGE, fluorographed with Enlightening (NEN), and exposed overnight at $-70^{\circ} \mathrm{C}$. For methylation assays, COS cells were labelled for $18 \mathrm{~h}$ with $200 \mu \mathrm{Ci}$ of $\left[\right.$ methyl- $\left.{ }^{3} \mathrm{H}\right]$ methionine (NEN) per $\mathrm{ml}$, and Rab proteins were immunoprecipitated with anti-Rab6 antibodies. Labelled Rab proteins were isolated from SDS-gels and subjected to alkaline hydrolysis as described previously $(16,23)$.

Western blotting (immunoblotting). Aqueous and detergent-enriched phases of Triton X-114-partitioned, nonlabelled COS1 cell lysates or equal proportions of S100 and P100 fractions were precipitated with $10 \%$ trichloroacetic acid on ice for $1 \mathrm{~h}$. The precipitated proteins were collected by centrifugation, washed three times with $1 \mathrm{ml}$ of cold acetone, dried, and taken up in Laemmli sample buffer (42). Following SDS-PAGE, the proteins were transferred to nitrocellulose by using a semidry blotting system (Pharmacia). The filter was blocked overnight in phosphate-buffered saline (PBS) containing 0.1\% Tween 20 (PBST) and 5\% dried milk (PBST $+\mathrm{M})$ and then incubated for $1 \mathrm{~h}$ with anti-Myc monoclonal antibody 9E10 diluted $1 / 4,000$ in PBST $+M$. After three washes with PBST, the filter was incubated for 1 $h$ with an anti-mouse horseradish peroxidase conjugate (NA931; Amersham) diluted $1 / 1000$ in PBST $+M$, then 
washed extensively, and developed by using an enhanced chemiluminescence (ECL) detection kit (Amersham) according to the manufacturer's instructions. Exposure times on Hyperfilm-ECL (Amersham) ranged from $15 \mathrm{~s}$ to $10 \mathrm{~min}$.

MDCK microinjection and immunofluorescence. MDCK cells growing on glass coverslips were microinjected in the nucleus with plasmid DNA at a concentration of $50 \mu \mathrm{g} / \mathrm{ml}$. After $18 \mathrm{~h}$ at $37^{\circ} \mathrm{C}$, the cells were permeabilized with a solution of $0.5 \%$ saponin- $0.2 \%$ bovine serum albumin (BSA) in PBS for $3 \mathrm{~min}$ and fixed in $4 \%$ formaldehyde in PBS for 20 min. The coverslips containing the fixed cells were washed for $30 \mathrm{~min}$ in a solution of $0.05 \%$ saponin-0.2\% BSA in PBS. All further washes and incubations were also performed in this solution. For detection of Myc-tagged proteins, the cells were incubated in anti-Myc mouse monoclonal antibody 9E10 ascites fluid diluted 1:200 for $1 \mathrm{~h}$ and then in goat fluorescein isothiocyanate-conjugated anti-mouse immunoglobulin $\mathrm{G}$ second antibody (Pierce) diluted 1:500 for $1 \mathrm{~h}$. For detection of endogenous Rab6, cells were incubated in affinity-purified polyclonal rabbit anti-Rab6 serum diluted 1:20 for $1 \mathrm{~h}$ and then in goat fluorescein isothiocyanateconjugated anti-rabbit immunoglobulin $G$ second antibody (Pierce) diluted 1:1250 for $1 \mathrm{~h}$. The coverslips were then mounted in Moviol mountant containing $0.1 \%$ p-phenyldiamine and examined with a Bio-Rad MRC 600 confocal imaging system in conjunction with a Nikon Optiphot fluorescence microscope and $60 \times$ Planapo objective lens.

For brefeldin A experiments, Swiss 3T3 cells growing on coverslips were microinjected in the nucleus with plasmid DNA as described above. After $18 \mathrm{~h}$ at $37^{\circ} \mathrm{C}$, cells were either permeabilized, washed, and fixed as described above or first incubated in brefeldin A at $5 \mu \mathrm{g} / \mathrm{ml}$ for $15 \mathrm{~min}$ before permeabilization, washing, and fixation. Staining was carried out as for MDCK cells.

Yeast methods. The ypt6 null mutant GL72 (MAT $\alpha$ ypt6::LEU2 his3) (kindly provided by D. Gallwitz) was crossed with a standard laboratory strain to obtain RS80-5A (MAT $\alpha$ ypt6::LEU2 ura3). RS80-5A was transformed with wild-type and C-terminal mutant Rab6 yeast expression plasmids. Wild-type and mutant Rab6 coding sequences were transferred into the yeast expression vector pNV11, which utilizes the $T D H 3$ (glyceraldehyde-3-phosphate dehydrogenase) promoter (kindly provided by M. Ruggieri). For each plasmid, four independent $\mathrm{Ura}^{+}$transformants were patched onto synthetic medium plates lacking uracil, grown at the permissive temperature $\left(30^{\circ} \mathrm{C}\right)$ for 1 day, and replica plated onto synthetic medium plates, which were then incubated at either 30 or $37.5^{\circ} \mathrm{C}$. Complementation of the ypt6 null mutation was assessed by the ability of the plasmids to restore growth at $37.5^{\circ} \mathrm{C}$. For some transformants, growth at $37.5^{\circ} \mathrm{C}$ in liquid culture was monitored with a Klett colorimeter.

To study expression levels of mutant Rab proteins, $25-\mathrm{ml}$ cultures of each transformant, and RS80-5A as control, were grown in synthetic medium with $\mathrm{Ura}^{+}$selection at $30^{\circ} \mathrm{C}$ to a density of $3 \times 10^{7}$ cells per $\mathrm{ml}$. The yeast cells were collected by centrifugation and resuspended in $500 \mu$ l of PBS containing $1 \mathrm{mM}$ dithiothreitol and $1 \mathrm{mM}$ phenylmethylsulfonyl fluoride. Glass beads were added, and the tubes were vortexed six times for $30 \mathrm{~s}$ each time. The lysates were clarified by centrifugation at $1,000 \times g$. Aliquots of each lysate were precipitated with $95 \%$ acetone (final concentration), and the precipitated proteins were resolved by SDSPAGE. Western blotting was carried out with 9E10 as the primary antibody.

\section{RESULTS}

Strategy for designing Rab6 proteins with mutant $\mathrm{C}$ termini. Wild-type Rab6 terminates in a C-terminal $\mathrm{C}_{1} \mathrm{XC}_{2}$ motif. This sequence has been shown previously to be geranylgeranylated on both of the $C_{1}$ and $C_{2}$ cysteines by the enzyme GGTase II. Following geranylgeranylation of the $\mathrm{C}_{2}$ cysteine, this residue is methyl esterified. To generate mutant Rab6 proteins that had a different lipid combination at the $\mathrm{C}$ terminus, we replaced the $\mathrm{C}$-terminal $\mathrm{CXC}$ motif with the sequence $\mathrm{C}_{1} \mathrm{XC}_{2} \mathrm{AAL}$ (where $\mathrm{A}=$ aliphatic amino acid and $\mathbf{L}=$ leucine) to create a substrate for the enzyme GGTase I, which recognizes the CAAL C-terminal motif. Following geranylgeranylation of the $\mathrm{C}_{2}$ cysteine, the AAL amino acids are removed by proteolysis and the $C_{2}$ carboxyl group is methylated. In the context of a prenylated, methylated cysteine, the $C_{1}$ cysteine is now an acylation site for the palmitoyl coenzyme A transferase that palmitoylates the Ras proteins. Thus, although completely different enzymes modify the mutant Rab protein, the net effect is simply the replacement of the $C_{1}$ geranylgeranyl group with palmitate. Similarly, a palmitoylated and farnesylated Rab6 protein was generated by replacing the $\mathrm{CXC}$ motif with a $\mathrm{C}_{1} \mathrm{XC}_{2} \mathrm{AAX}$ sequence so that the first processing step would be carried out on $C_{2}$ by farnesyltransferase and palmitoylation on $C_{1}$ would be carried out by palmitoyltransferase. In this case, both geranylgeranyl groups found on wild-type Rab6 are replaced, the $C_{1}$ with palmitate and the $C_{2}$ with farnesyl. In addition, three Rab proteins were designed to have single prenoid groups at the $\mathrm{C}$ terminus. The CXC motif was replaced either with a CAAX sequence to generate a farnesylated Rab protein or with a CAAL sequence to generate a singly geranylgeranylated $\mathrm{Rab}$ protein. Certain $\mathrm{Rab}$ proteins terminate in a $C_{1} C_{2}$ motif which is geranylgeranylated by GGTase II but probably only on $C_{1}$, since $C_{2}$ is not methylated $(42,50)$. We therefore constructed a Rab6 protein with a $C_{1} C_{2}$ motif in place of the wild-type $C_{1} X_{2}$ sequence to compare it with the CAAL mutant and hence address whether methylation of the $\mathrm{C}$ terminus has any consequence for localization and function of Rab proteins. The structures of these mutant Rab proteins are summarized in Table 1, which lists the actual amino acid sequences used in constructing the different C-terminal motifs. It should be noted that only the C-terminal motifs of Rab6 are changed in each case, and therefore all of the mutant proteins contain the complete wild-type Rab6 sequence upstream of the CXC motif. In addition, since Rab6 is expressed at a high level in most mammalian cells (22), a duplicate set of constructs with $\mathrm{N}$-terminal Myc epitope tags (1) was made to allow discrimination between endogenous and mutant Rab6 proteins during immunolocalization.

Rab6 C-terminal mutants are processed in vitro and in vivo. We have previously cloned CKCVLS, CKCCIL, CVLS, and CCIL sequences from wild-type Ras and a mutant Ras onto heterologous proteins and confirmed that they are processed as described in Table $1(25,34)$. However, we wished to verify that the expected processing events would occur when these sequences were cloned onto a different Ras-related protein, Rab6. First, to confirm that the mutant Rab6 proteins were prenylated as predicted, the cDNAs were cloned into pGEM vectors, and mRNA was transcribed and translated in vitro in a nuclease-treated rabbit reticulocyte lysate labelled with $\left[{ }^{3} \mathrm{H}\right]$ mevalonic acid (26). An analysis of the radiolabelled prenoids attached to the proteins showed that the RabCSC (wild type), RabCC, and 
TABLE 1. Summary of C-terminal mutant Rab6 proteins and their expected posttranslational modifications

\begin{tabular}{|c|c|c|c|c|c|c|c|c|c|c|}
\hline \multicolumn{2}{|c|}{ C-terminal motif } & \multicolumn{6}{|c|}{ Processing by ${ }^{a}$ : } & \multicolumn{3}{|c|}{ C-terminal structure ${ }^{b}$} \\
\hline Actual $^{c}$ & Substrate $^{d}$ & $\overline{\text { FTase }}$ & GGTase I & GGTase II & Protease & Methylase & PalmTase & $\mathrm{C}_{1}$ & $\mathrm{C}_{2}$ & Methyl \\
\hline CSC & $\mathrm{C}_{1} \times \mathrm{C}_{2}$ & & & + & & + & & GG & GG & + \\
\hline $\mathrm{CC}$ & $\mathrm{C}_{1} \mathrm{C}_{2}$ & & & + & & & & GG & 0 & 0 \\
\hline CVLS & $\mathrm{C}_{2} \mathrm{AAX}$ & + & & & + & + & & 0 & $\mathrm{~F}$ & + \\
\hline $\mathrm{CCIL}^{e}$ & $\mathrm{C}_{2} \mathrm{AAL}$ & & + & & + & + & & 0 & GG & + \\
\hline CKCVLS & $\mathrm{C}_{1} \times \mathrm{C}_{2} \mathrm{AAX}$ & + & & & + & + & + & Palm & $F$ & + \\
\hline CKCCIL & $\mathrm{C}_{1} \times \mathrm{C}_{2} \mathrm{AAL}$ & & + & & + & + & + & Palm & GG & + \\
\hline
\end{tabular}

${ }^{a}+$, the motif is expected to be processed by the enzyme(s) indicated. FTase, Farnesyltransferase; Palm Tase, palmitoyltransferase.

$b$ The fully processed C-terminal structure following modification. GG, geranylgeranylation; F, farnesylation; Palm, palmitoylation. The transferases which carry out these lipid modifications are denoted by the suffix "Tase" and are described in the text.

$c$ The actual motifs which replaced the wild-type C-terminal sequence.

${ }^{d} \mathrm{C}_{1}$ and $\mathrm{C}_{2}$, the key cysteine residues which are modified by the prenyl- and palmitoyltransferases as discussed in the text.

$e$ Although the CCIL motif has a Cys residue in what is the $A_{1}$ position of the CAAL consensus sequence, it can still serve as a substrate for GGTase $I$ (25, $37,42)$.

RabCCIL proteins were geranylgeranylated, while the RabCVLS protein was farnesylated.

To further investigate in vivo posttranslational processing, wild-type and mutant Rab6 proteins were transiently expressed in COS1 cells. The transfected cells were pulselabelled with $\left[{ }^{35} \mathrm{~S}\right]$ methionine, chased in normal medium for $6 \mathrm{~h}$, and lysed in Triton X-114. The aqueous and detergentenriched phases were immunoprecipitated with an anti-Rab6 serum (22). Figure 1 shows that all of the C-terminal mutant Rab6 proteins were processed in COS1 cells. In each case, 30 to $50 \%$ of the labelled Rab protein chases from a slowermigrating, aqueous-partitioning form into a faster-migrating, prenylated, detergent-partitioning form. Interestingly, the RabCC was processed efficiently, showing that Rab6 contains the appropriate additional protein sequences or conformation to permit processing of $\mathrm{CC}$ and $\mathrm{CXC}$ motifs. A similar result was recently obtained with $\operatorname{Rab} 2$ (35). The extent of processing of the various C-terminal mutant proteins was similar to that of the wild-type protein (Fig. 1). The extent of processing with $\mathrm{CAAX} / \mathrm{L}$ motifs on the $\mathrm{C}$ terminus of Rab6 was slower, however, than the extent to which these motifs were processed when cloned onto the $\mathrm{C}$ terminus of the heterologous protein, protein $\mathrm{A}$. When COS1 cells overexpressing the $\mathrm{C}$-terminal mutant Rab6 proteins were labelled with $\left[{ }^{3} \mathrm{H}\right]$ palmitate, only RabCKCCIL and RabCKCVLS proteins incorporated label (Fig. 1). Rab6, RabCC, and RabCCIL proteins were then expressed in COS1 cells and labelled for $18 \mathrm{~h}$ with [methyl ${ }^{3} \mathrm{H}$ ]methionine. A vaporphase equilibration assay (16) showed that Rab6 and RabCCIL were methyl esterified whereas RabCC was not.

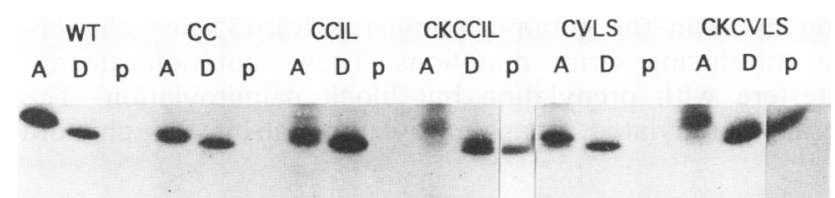

FIG. 1. COS1 cells transiently expressing the Rab6 C-terminal mutants described in Table 1 were pulse-labelled for $10 \mathrm{~min}$ with $\left.{ }^{35} \mathrm{~S}\right]$ methionine and chased for $6 \mathrm{~h}$ with cold methionine. Cells were lysed in Triton X-114, the lysates were partitioned, and the aqueous phase (A) and detergent phase (D) were separated. An aliquot of cells from each transfection was also labelled with $\left[{ }^{3} \mathrm{H}\right]$ palmitic acid (p). Samples were immunoprecipitated with anti-Rab6 antibodies, resolved by SDS-PAGE, and fluorographed. The ${ }^{35} \mathrm{~S}$-labeled lanes (A and D) are overnight exposures, and the ${ }^{3} \mathrm{H}$-labeled lanes are 2-week exposures.
Taken together, these data from a combination of wellvalidated in vitro and in vivo assays are fully consistent with the modifications predicted for each of the mutants in Table 1. Essentially identical results (not shown) were obtained with the $\mathrm{N}$-terminal Myc-tagged Rab constructs, in agreement with earlier reports that this $\mathrm{N}$-terminal addition does not compromise the posttranslational processing of Rasrelated proteins (1).

Farnesylation alone is insufficient for targeting Rab6 to the Golgi complex. The subcellular distribution of C-terminal mutant Myc-tagged Rab6 proteins was investigated in COS1 cells. Cells were fractionated, and equal proportions of the S100 and P100 fractions were resolved by SDS-PAGE and Western blotted with 9E10, an anti-Myc monoclonal antibody. Figure $2 \mathrm{~A}$ shows that $50 \%$ of the wild-type Rab6 and mutant RabCC proteins were found in the P100 fraction. Some $30 \%$ of the RabCCIL protein expressed in COS cells was P100 associated, while the extent of membrane association of the geranylgeranylated, palmitoylated RabCKCCIL protein approached that of the wild type (Fig. 2A). By contrast, the RabCVLS mutant fractionated completely in the cytosolic S100 fraction, but $30 \%$ of the farnesylated and palmitoylated RabCKCVLS protein bound to cellular mem-

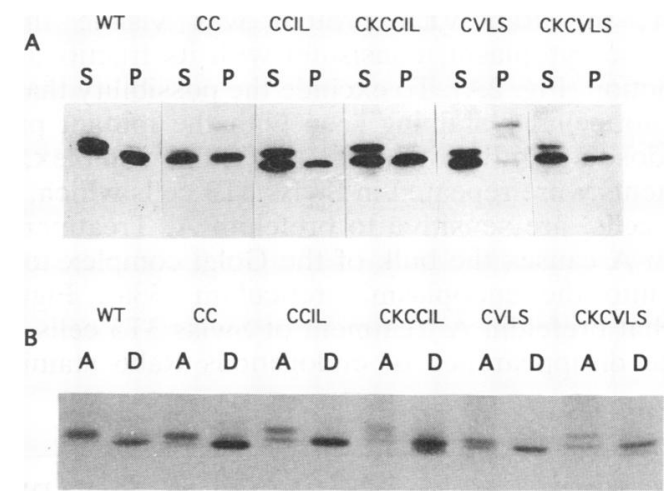

FIG. 2. (A) COS1 cells expressing the Myc-tagged Rab6 mutant proteins were fractionated into P100 (P) and S100 (S) fractions. Equal proportions of all fractions were resolved by SDS-PAGE and Western blotted with an anti-Myc monoclonal antibody. (B) COS1 cells expressing the Rab6 C-terminal mutants were pulse-labelled for 10 min with $\left[{ }^{35}\right.$ S $]$ methionine and chased for $24 \mathrm{~h}$ with cold methionine. Lysates were prepared and analyzed as described in the legend to Fig. 1. WT, wild type. 
branes. Figure 2A also shows that for all of the Rab6 proteins with $\mathrm{CAAX} / \mathrm{L}$ motifs, two species with different electrophoretic mobilities were found in the S100 fraction. Both partitioned into the aqueous phase of Triton X-114 except with RabCVLS, in which case half of the fast-migrating cytosolic form was detergent partitioning. A fast-migrating hydrophilic form was not observed with the wild-type or the RabCC mutant protein. Figure $2 B$ shows that the fastmigrating hydrophilic form of the RabCCIL, RabCKCCIL, RabCVLS, and RabCKCVLS proteins is clearly apparent 24 $\mathrm{h}$ after the cells were pulse-labelled but is not visible after a 6-h cold chase (Fig. 1). This lower-molecular-weight hydrophilic form may therefore represent either processed Rab which has been deprenylated or, more probably, nonprocessed Rab which has undergone proteolysis. Hrycyna and Clarke (33) recently described a cytosolic carboxypeptidase which specifically recognizes proteins with unprocessed C-terminal CAAX sequences. This or a related enzyme may be responsible for proteolysing the unprocessed Rab proteins which accumulate in the COS1 cells as a result of the slower rate of processing of the CAAX/L motifs when present at the $\mathrm{C}$ terminus of Rab6.

We next investigated the localization of the Myc-tagged Rab6 proteins in MDCK cells by indirect immunofluorescence following microinjection of plasmid DNA. To study only membrane-bound Rab6 protein, the MDCK cells were permeabilized before fixation to wash out cytosolic soluble forms. With this protocol, the staining pattern with 9E10 in cells overexpressing Myc-tagged wild-type Rab6 was identical to that seen when endogenous Rab6 was visualized in noninjected cells with an anti-Rab6 serum (Fig. 3). These results demonstrate that the addition of a Myc epitope at the $\mathrm{N}$ terminus does not affect the subcellular localization of Rab6 protein and clearly show that overexpression of Rab6 in MDCK cells does not cause mislocalization by saturating the Golgi complex. A previous report (2) suggesting aberrant localization of overexpressed Rab6 did not take account of the significant amount of nonprocessed protein. Figure 3 also shows that despite different posttranslational modifications, the RabCC, RabCCIL, RabCKCCIL, and RabCKCVLS proteins all appeared to be localized to the Golgi complex. The farnesylated RabCVLS protein, being soluble, was washed out of the cells, although very faint nuclear staining was evident (Fig. 3). In cells permeabilized after fixation, however, the RabCVLS protein was visible diffusely through the cytoplasm, consistent with its fractionation to S100 fraction (Fig. 2A). To exclude the possibility that some of the intracellular staining seen with the mutant proteins was endosomal rather than in the Golgi complex, these experiments were repeated in Swiss 3T3 cells which, unlike MDCK cells, are sensitive to brefeldin A. Treatment with brefeldin A causes the bulk of the Golgi complex to redistribute into the endoplasmic reticulum (38a). Figure $4 b$ shows that brefeldin A treatment of Swiss 3T3 cells causes complete disappearance of endogenous Rab6 staining. In cells overexpressing Myc-tagged Rab6 (Fig. 4c and d), juxtanuclear staining is lost and replaced with a diffuse reticular staining. Exactly the same effect is seen in cells expressing the Myc-tagged RabCC, RabCCIL, and RabCKCCIL proteins (Fig. 4e to j), consistent with these proteins being Golgi complex localized to the same extent as the Myc-tagged wild-type Rab6 protein. Fifty percent of cells expressing Myc-tagged RabCKCVLS showed some persistence of juxtanuclear staining following brefeldin A exposure, although otherwise the extent and pattern of staining in the RabCKCVLS-expressing cells matched that seen in cells overexpressing Myc-tagged wild-type Rab6 (Fig. 4k and l). These data are consistent with the majority of the RabCKCVLS mutant being Golgi complex localized, although a proportion may be mislocalized to another structure.

Golgi complex-targeting sequences of Rab6 are located outside the C-terminal hypervariable domain. Figures 3 and 4 show that the palmitoylated and farnesylated RabCKCVLS protein was targeted to the Golgi complex. This combination of lipids has been shown previously to function as a plasma membrane-targeting signal both for Ras and for heterologous proteins $(25,34)$. One interpretation of these data is that there are domains within Rab6 that prevent palmitoylated, farnesylated Rab6 from localizing to the plasma membrane. Since Chavrier et al. (14) have shown that the C-terminal hypervariable domains of Rab5 and Rab7 are involved in subcellular localization, we investigated whether this domain in Rab6 contains sequences which override the plasma membrane-targeting function of the palmitic acid-prenoid combination. A SpeI restriction site was introduced into H-Ras at amino acid position 144 to correspond with a SpeI site in Rab6 at amino acid 155. These are equivalent residues because Rab6 has an extra 11 amino acids at the $\mathbf{N}$ terminus when aligned with Ras. The C-terminal 45 amino acids of Rab6 and H-Ras were then exchanged. This Rab155-Ras chimeric protein has a C-terminal CKCVLS motif but lacks the Rab6 hypervariable domain. A geranylgeranylated form of the Rab155-Ras chimera was also constructed by replacing the CVLS sequence of Rab155-Ras with a geranylgeranylated CCIL motif. The chimeric proteins were processed as determined by Triton $\mathrm{X}-114$ phase partitioning, both incorporated label from $\left[{ }^{3} \mathrm{H}\right]$ palmitic acid, and both were P100 associated (Fig. 5 and data not shown). Immunofluorescence studies in MDCK cells expressing these chimeric Rab155-Ras proteins now showed staining of both plasma membrane and Golgi complex (Fig. 6), consistent with the notion that the Rab6 hypervariable region was preventing plasma membrane localization. To confirm that palmitic acid was responsible for the partial plasma membrane localization of the Rab155-Ras chimeric protein, we removed the cysteine acylation sites upstream of the C-terminal prenylation motif in the geranylgeranylated Rab155-Ras chimera by introducing serine mutations. These mutations do not interfere with prenylation but block palmitoylation. The geranylgeranylated, nonpalmitoylated Rab155-Ras chimera

FIG. 3. MDCK cells were microinjected with plasmid DNA and analyzed $18 \mathrm{~h}$ later. Cells were permeabilized with saponin and washed before fixation to remove all soluble proteins. (a) MDCK cells stained with an affinity-purified anti-Rab6 antibody (22). Endogenous Rab6 is well expressed and shows the localization of the Golgi complex. (b) MDCK cells microinjected with Myc-tagged Rab6 and stained with an anti-Myc antibody. The localization of this protein is identical to that seen in panel a. There is no staining of any intracellular structure with this antibody in noninjected MDCK cells (not shown). (c) MDCK cells injected with Myc-tagged RabCC. (d) MDCK cells injected with Myc-tagged RabCCIL. (e) MDCK cells injected with Myc-tagged RabCKCCIL. (f) MDCK cells injected with Myc-tagged RabCKCVLS. (g) MDCK cells injected with Myc-tagged RabCVLS. The cells in panels $\mathrm{c}$ to f were stained with the anti-Myc antibody 9E10. Note that the Golgi complex staining in panels $\mathrm{c}$ to $\mathrm{f}$ is identical to that seen with wild-type Rab6 shown in panels a and b. No Golgi complex staining is seen in cells microinjected with Myc-tagged RabCVLS (g). 

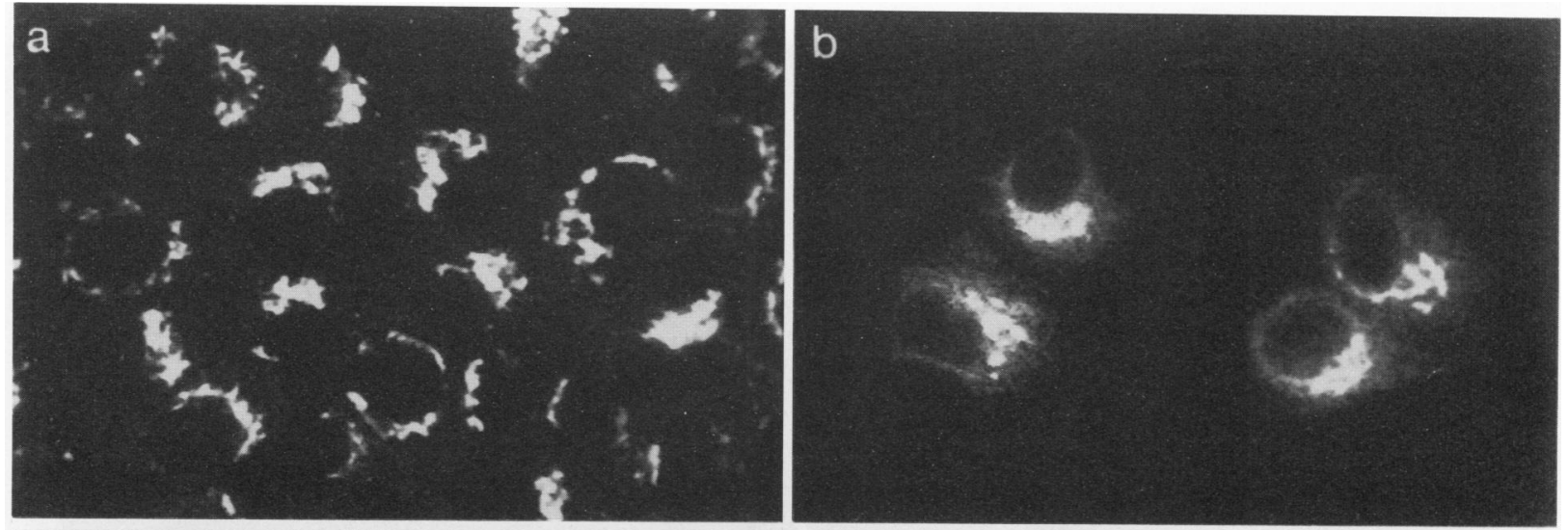

C

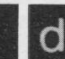

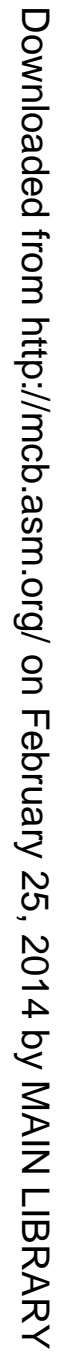

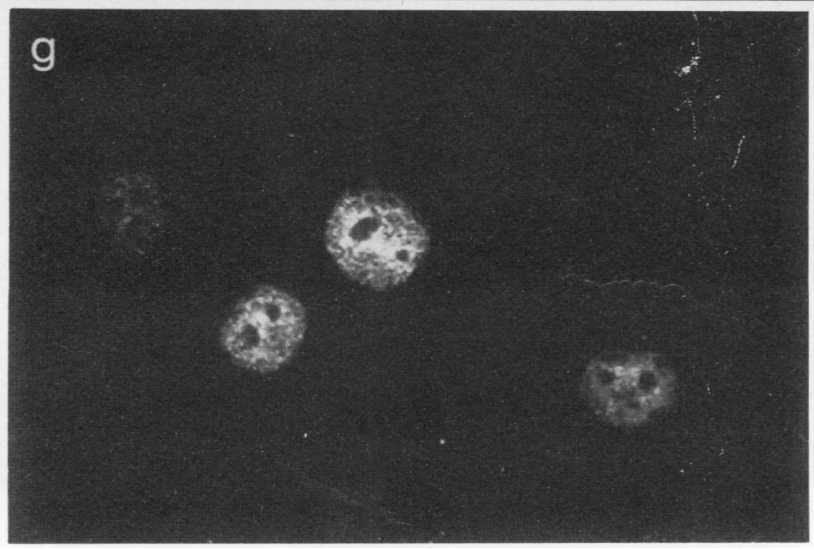




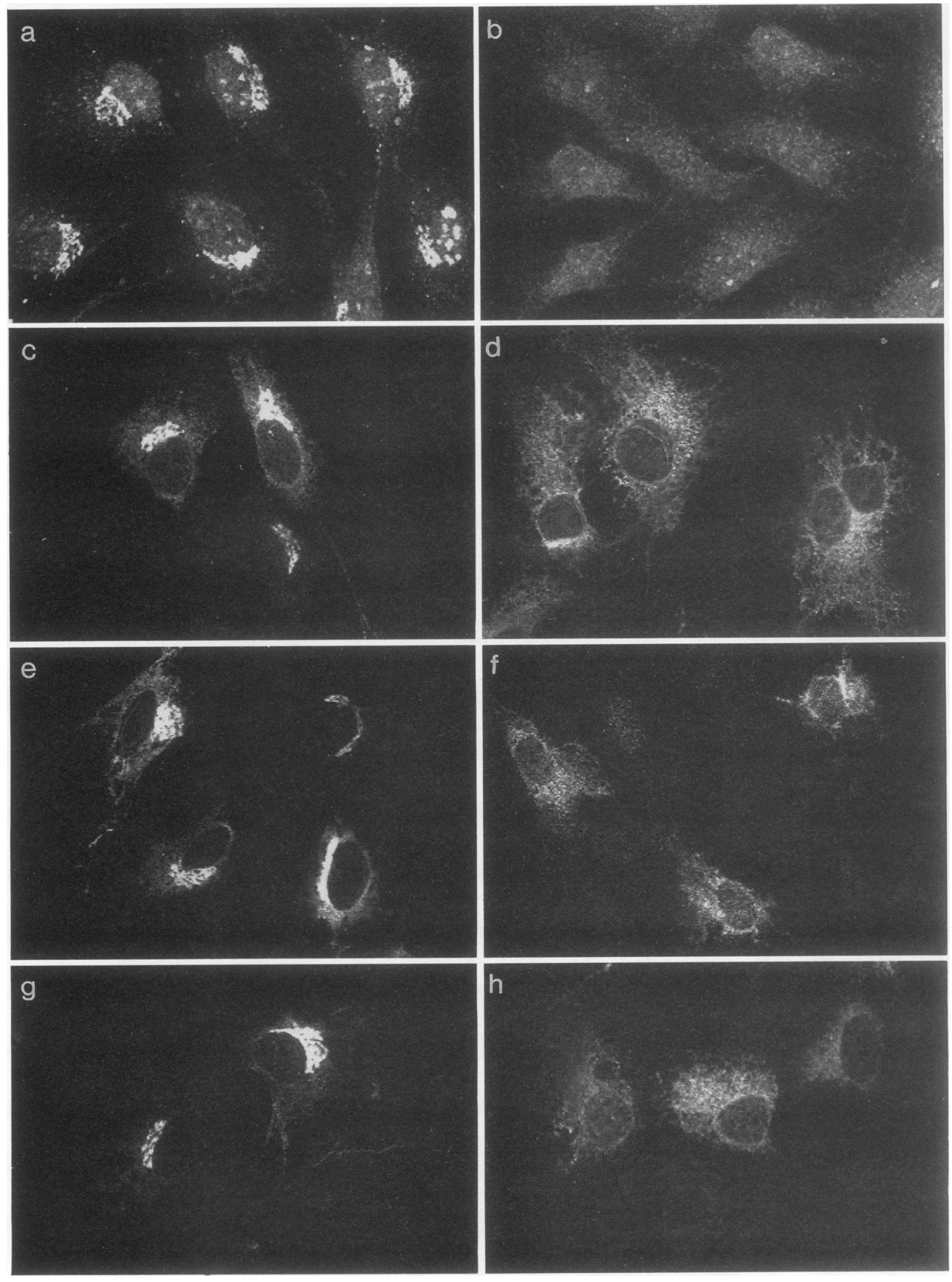

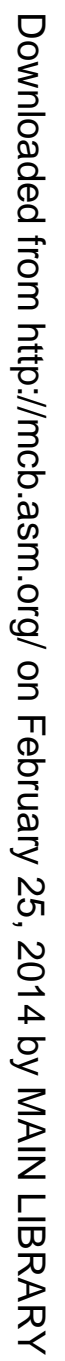



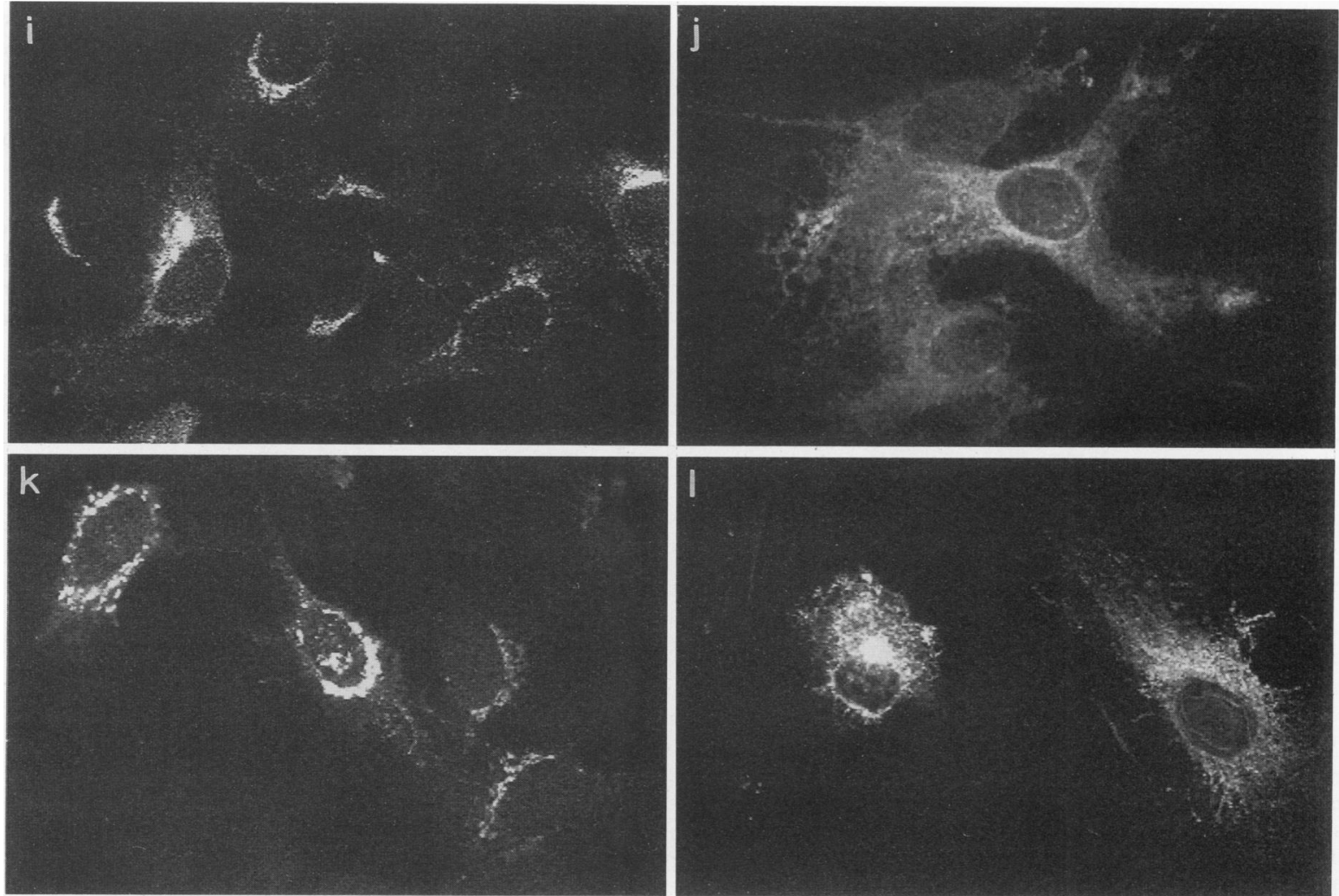

FIG. 4. Swiss $3 T 3$ cells show redistribution of the Golgi complex into the endoplasmic reticulum upon exposure to brefeldin A (38a). (a, c, e, g, i, and k) Swiss 3T3 cells that have been microinjected with plasmid DNA and $18 \mathrm{~h}$ later permeabilized, washed, and fixed; (b, d, f, $\mathrm{h}, \mathrm{j}$, and l) cells prepared in the same manner except that they were treated with brefeldin $\mathrm{A}$ immediately before permeabilization; (a and b) endogenous Rab6 stained with antiRab6; ( $c$ and d) cells injected with Myc-tagged Rab6; ( $e$ and $f$ ) cells injected with Myc-tagged RabCC; ( $g$ and $h$ ) cells injected with Myc-tagged RabCCIL; ( $i$ and j) cells injected with Myc-tagged RabCKCCIL; (k and l) cells injected with Myc-tagged RabCKCVLS. The cells in panels a and $b$ were stained with affinity-purified anti-Rab6. Note that brefeldin treatment causes complete loss of the juxtanuclear staining. The cells in panels $\mathrm{c}$ to $\mathrm{l}$ were stained with anti-Myc antibody. Brefeldin causes complete loss of juxtanuclear staining in cells expressing Rab6, RabCC, RabCCIL, and RabCKCCIL, confirming that these proteins are exclusively in the Golgi complex. Of the cells expressing RabCKCVLS, 50\% also show complete loss of juxtanuclear staining upon brefeldin treatment; the remainder show loss of the majority of such staining. This finding indicates that while most of RabCKCVLS is Golgi complex associated, a small amount may be endosomal.

fractionated in the P100 fraction (Fig. 5), and immunolocalization in MDCK cells showed it to be exclusively in the Golgi complex (Fig. 6), although the staining was less intense and slightly more diffuse than with full-length Rab6 (compare with Fig. 3). Preliminary experiments in Swiss 3T3 cells suggest that this staining is brefeldin A sensitive. As an additional control, we investigated the localization of a full-length, Myc-tagged $\mathrm{H}$-Ras protein with identical C-terminal modifications to the Golgi complex-localized Rab155Ras chimera with respect to geranylgeranylation and no palmitoylation. This mutant H-Ras protein was P100 associated, but as shown in Fig. 6, it did not localize to the Golgi complex or plasma membrane. In addition to demonstrating the key role of palmitic acid in plasma membrane targeting, these results suggest that Golgi complex-targeting sequences of Rab6 are located, at least in part, in the N-terminal 155 amino acids.

The effector domain of Rab6 is required for Golgi localization. To further define the $\mathrm{N}$-terminal targeting sequence, we constructed a more extensive series of chimeras in which various amounts of $\mathrm{H}$-Ras sequence were used to replace homologous sequences at the $\mathbf{N}$ terminus of the nonpalmitoylated, geranylgeranylated Rab155-Ras chimera (Fig. 7).
All of these chimeras were stably expressed and membrane associated when analyzed in COS1 cells, but as summarized in Fig. 7, none showed any affinity for the Golgi complex when analyzed by immunofluorescence in MDCK cells, implying that the $\mathrm{N}$-terminal 71 amino acids of Rab6 are required for Golgi complex localization of the Rab155-Ras chimera. To more precisely map potential sites of interaction with a Golgi complex protein, we next replaced short sequences in the $\mathbf{N}$-terminal 71 amino acids of full-length wild-type Rab6 with homologous sequences from Ras. We argued that loops predicted to be on the outside of the Rab6 protein would be the domains of the protein most likely to be involved in binding to the Golgi complex. Also, in an attempt to maintain as normal a conformation of the mutated protein as possible, we replaced complete loops of Rab6 with the corresponding complete loops of Ras. Therefore, the effector domain of Rab6 (loop 2) was replaced with the Ras effector domain (to give Rab-L2Ras), and loop 3 of Rab6 was replaced with loop 3 of Ras (to give Rab-L3Ras) (Fig. 7). A third chimera (Rab-L2+L3Ras) in which both loops were replaced with Ras sequence was constructed. All three chimeras were processed to the same extent as wild-type Rab6 in COS cells and were membrane associated (data not 
A

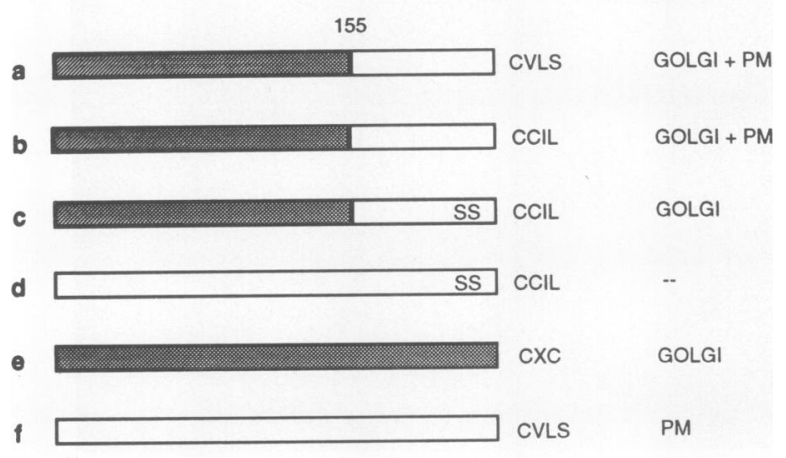

B

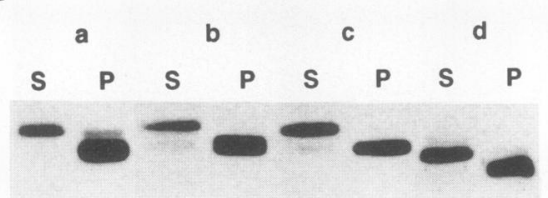

FIG. 5. (A) The Rab-Ras chimeric proteins (a to c) have the $\mathrm{N}$-terminal 155 amino acids of Rab6 (e) fused to the C-terminal 45 amino acids of $\mathrm{H}$-Ras (f). Rab6 has an extra 11 amino acids at the $\mathbf{N}$ terminus when aligned with $\mathrm{H}$-Ras, and therefore the residue equivalent to 155 in Rab6 is 144 in H-Ras. The C-terminal sequences of the chimeras are shown; chimera a is palmitoylated and farnesylated, chimera $b$ is palmitoylated and geranylgeranylated, and chimera $\mathrm{c}$ and control protein $\mathrm{d}$ are only geranylgeranylated because cysteines 181 and 184 in the H-Ras hypervariable domain have been mutated to serines (SS). The localization data shown in Fig. 6 are summarized. PM, plasma membrane; --, no binding to the Golgi complex or plasma membrane. (B) COS1 cells expressing chimeras a to $\mathrm{c}$ and the $\mathrm{H}$-Ras geranylgeranylated, nonpalmitoylated control (chimera d) were fractionated into S100 (S) and P100 (P) fractions, and the same proportion of each was Western blotted with the anti-Myc monoclonal antibody $9 \mathrm{E} 10$. All of these proteins bind to membranes.

shown and Fig. 7). The wild-type $\mathrm{CXC} \mathrm{C}$ terminus was present in these chimeras, which indicates that the conformation of the mutant proteins was sufficiently close to that of a wild-type Rab protein to allow processing by GGTase II. Interestingly, an analysis of the localization of these proteins in MDCK cells showed that the Rab6 effector domain was essential for Golgi complex targeting. In Fig. 8, it is clear that Rab-L2Ras and Rab-L2+L3R show very weak or no Golgi complex staining, while Rab-L3Ras shows wild-type Golgi complex staining. All proteins were expressed to the same extent in MDCK cells, as shown by the equivalent staining of cells fixed before permeabilization (Fig. 8).

Farnesylation alone does not allow Rab6 to complement the yeast ypt6 mutation. The ability of the C-terminal mutant Rab6 proteins to function in vivo was analyzed in yeast cells. The YPT6 gene encodes a Rab6 homolog, and disruption of this gene impairs growth at higher temperatures $(31,47 a)$. Complementation of this temperature-sensitive growth defect was tested following transformation of a ypt6 null mutant with plasmids which drive expression of either wild-type or C-terminal mutant Rab6 proteins. In a replicaplating assay, expression of the wild-type Rab6 protein restored growth at high temperature, as did expression of the other geranylgeranylated Rab6 proteins RabCC, RabCCIL, and RabCKCCIL (Fig. 9A). Expression of the farnesylated Rab6 protein RabCVLS did not complement ypt6, but expression of the palmitoylated and farnesylated mutant RabCKCVLS protein did complement ypt6 (Fig. 9A). Thus, the ability of the C-terminal mutant Rab6 proteins to complement the ypt6 temperature-sensitive growth defect correlates precisely with their ability to localize to the Golgi complex in mammalian cells. Notably, expression of the Rab155-Ras protein (chimera a in Fig. 5), which contains the H-Ras hypervariable C-terminal domain instead of the corresponding Rab6 region, functioned as well as wild-type Rab6 to complement ypt6 (Fig. 9A).

While performing the replica-plating assay, we noted that growth at the higher temperature of ypt6 mutants expressing RabCCIL was not as rapid as that of ypt6 mutants expressing wild-type Rab6, RabCC, or RabCKCCIL. To confirm this observation, we performed growth assays in liquid culture for ypt6 mutants expressing either wild-type Rab6, RabCC, or RabCCIL. Following a shift to $37.5^{\circ} \mathrm{C}$, ypt6 mutants not expressing any Rab6 protein ceased growth after approximately $2 \mathrm{~h}$ (Fig. 9B). In contrast, ypt6 mutants which expressed either wild-type Rab or RabCC continued to grow exponentially until reaching saturation (Fig. 9B). An intermediate growth response was observed with ypt6 mutants expressing RabCCIL. After $2 \mathrm{~h}$, these cells grew more slowly than ypt6 mutants expressing wild-type Rab6 or RabCC, eventually reaching a saturation density close to that obtained by ypt6 mutants expressing wild-type Rab6 (Fig. 9B and data not shown). Thus, while RabCCIL can function in yeast cells, it appears to function less well than Rab6 itself or RabCC.

To confirm that the growth defect with RabCCIL and the inability of RabCVLS to complement $y p t 6^{-}$was not simply due to a problem with expression, we investigated the steady-state level of expression in each of the transformants. Figure 9C shows that when grown at the permissive temperature, each of the transformed strains expressed a Myctagged Rab protein. The steady-state levels of expression of all of the mutant proteins were comparable (Fig. 9C).

\section{DISCUSSION}

The majority of Ras-related proteins terminate in cysteinecontaining $\mathrm{C}$-terminal motifs that direct prenylation with $\mathrm{C}_{15}$ farnesyl or $\mathrm{C}_{20}$ geranylgeranyl. It is striking that whereas Ras is farnesylated, most other Ras-related proteins are geranylgeranylated. The role of farnesylation coupled with a second signal such as palmitoylation or the presence of several basic residues in targeting Ras to the plasma membrane has been well characterized $(28,30)$, but the role that geranylgeranylation plays in membrane targeting and the biological function of other Ras-related proteins have not to date been carefully addressed. In this study, we have examined whether geranylgeranylation is absolutely required for the localization and biological function of the Ras-related protein Rab6 and mapped other domains in this protein that are required for its subcellular targeting. By making use of the known recognition sequences of the three characterized prenoid transferases and also the acyltransferase that palmitoylates the Ras proteins, we were able to replace the wild-type doubly geranylgeranylated, methylated $\mathrm{C}$ terminus of Rab6 with five different lipid combinations.

Although wild-type Rab6 is prenylated with two geranylgeranyl groups, we found that replacement of one of these geranylgeranyl groups with an acyl group, palmitic acid, did not affect its subcellular localization. Moreover, a 

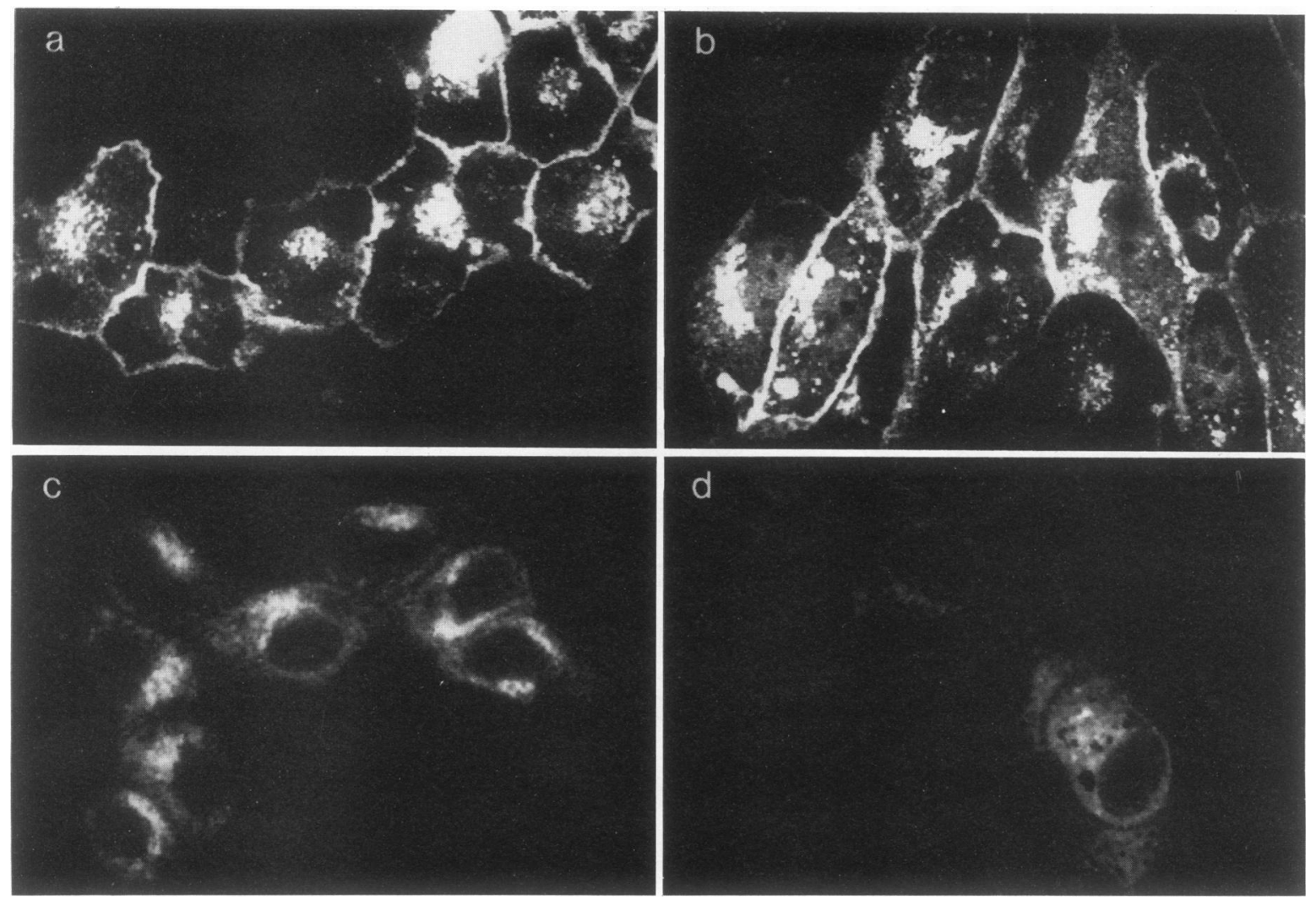

FIG. 6. MDCK cells were microinjected with expression plasmids. After $24 \mathrm{~h}$, the cells were permeabilized with saponin, washed, and fixed. Rab155-Ras chimeric proteins and the Ras control proteins (a to $\mathrm{d}$ in Fig. 5A) were visualized by immunofluorescence in a confocal microscope. The primary antibody used was the anti-Myc monoclonal antibody 9E10. (a) Rab155-Ras chimera a modified by palmitoylation and farnesylation; (b) Rab155-Ras chimera b modified by palmitoylation and geranylgeranylation; (c) Rab155-Ras chimera c modified by geranylgeranylation only; (d) H-Ras modified by geranylgeranylation only. In panels a and b, staining of both the plasma membrane and the Golgi complex is evident. Golgi complex staining alone is evident in panel c, although this staining is less intense than that seen with Myc-tagged Rab6 (compare with Fig. 3b). No plasma membrane staining nor Golgi complex staining is seen in panel d, although expression of the protein was confirmed in cells fixed before permeabilization (not shown).

single geranylgeranyl group also proved sufficient to localize the RabCCIL protein to the Golgi complex. This Golgi complex localization was unaffected by methylation of the $\mathrm{C}$ terminus, since the methylated RabCCIL protein and the nonmethylated RabCC protein were both correctly targeted. Replacement of both geranylgeranyl groups with a single farnesyl moiety, however, rendered Rab6 cytosolic. Interestingly, the combination of palmitoylation plus farnesylation restored Rab6 to the Golgi complex. One interpretation of these data is that a minimum degree of hydrophobicity of the $\mathrm{C}$ terminus of a $\mathrm{Rab}$ protein is required for its membrane association which cannot be provided by an isolated farnesyl group. In support of this hypothesis, it has recently been estimated that the hydrophobicity of geranylgeranyl is an order of magnitude greater than that of either farnesyl or palmitoyl (5). These data correlate with our previous observations that geranylgeranylated Ras proteins bind with significantly higher affinity to cellular membranes than farnesylated Ras proteins do and that the avidity of membrane binding of a palmitoylated and farnesylated Ras protein is similar to that of a geranylgeranylated protein $(25,30)$. Taken together, these data suggest that palmitoylation increases the hydrophobicity of a farnesylated Rab6 C terminus sufficiently to permit membrane binding. It is evident from these experiments that a single geranylgeranyl group is sufficient for the subcellular localization of Rab6, raising the question of whether the second geranylgeranyl moiety present in Rab6 and other CXC-containing Rab proteins serves some other function.

Although Rab proteins are all prenylated with one or two geranylgeranyl groups, they are localized to different subcellular structures. Thus, while lipid modification is required for the membrane binding of Rab proteins, other features are clearly necessary for specific subcellular targeting. In the Ras proteins, these additional sequences comprise a palmitoylation site or a polylysine domain which is located adjacent to the CAAX motif in the $\mathrm{C}$-terminal hypervariable domain. The targeting sequences of other Ras-related proteins have been thought to be similarly situated. Evidence for this has recently been provided by Chavrier et al. (14), who showed that exchanging the hypervariable domains of Rab5 and Rab7 switched their specific subcellular localization. We found in this study, however, that when the hypervariable domain of Rab6 was replaced with that of a geranylgeranylated, nonpalmitoylated Ras protein, the chimeric protein remained in the Golgi complex. The full-length geranylgeranylated, nonpalmitoylated mutant Ras protein, which provided the C-terminal sequences for this chimera, showed no affinity for the Golgi complex or plasma membrane, in agreement with previous data (25). However, the 


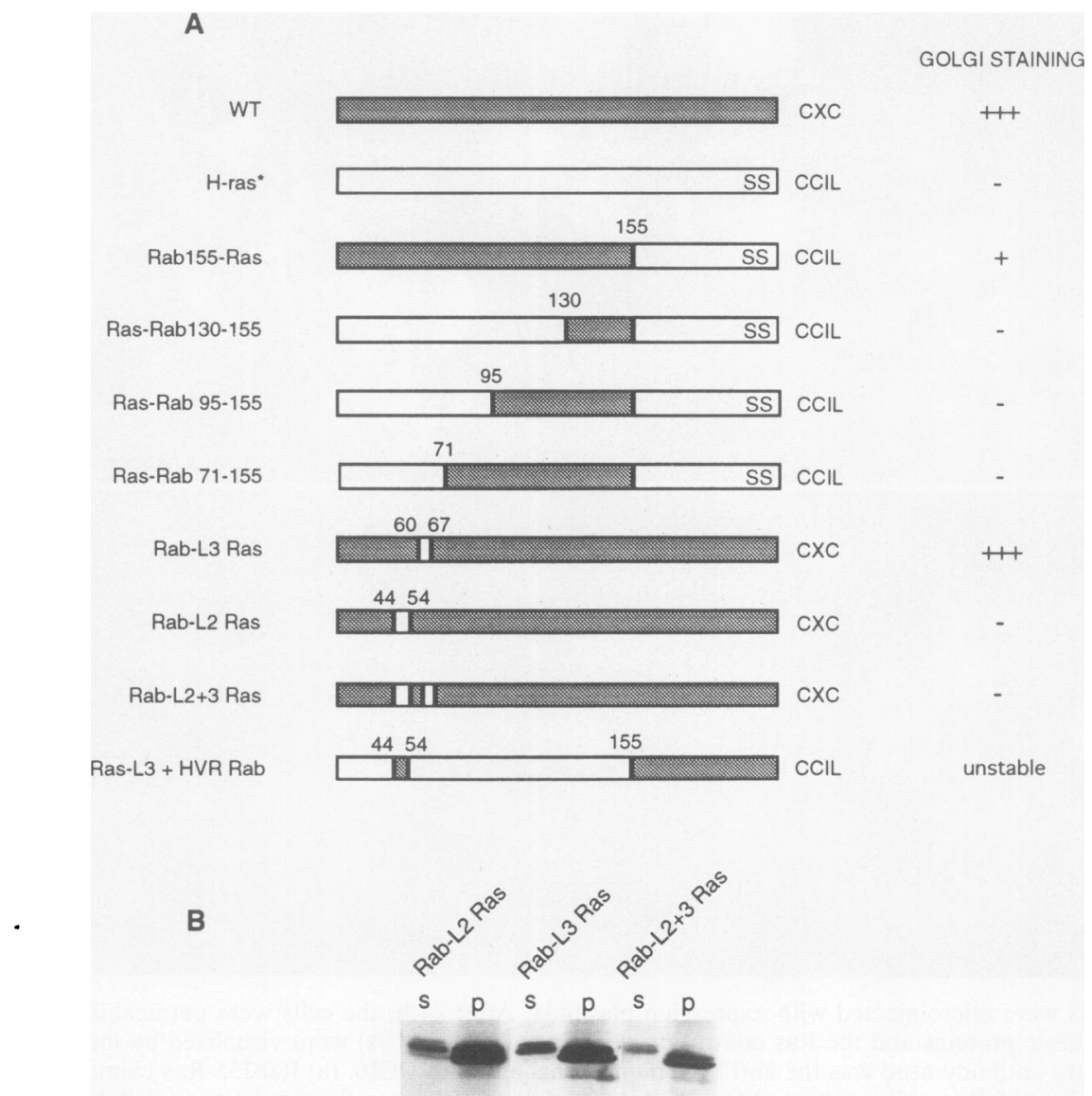

FIG. 7. (A) Structures of the Rab-Ras chimeras used to map the involvement of the Rab6 effector domain in Golgi complex targeting. The C-terminal motif present, either CCIL or CXC, is given for each chimera. Note that the Ras sequence used to construct these chimeras (indicated by *) has a CCIL C-terminal motif and has had the palmitoylation sites Cys-181 and Cys-184 mutated to Ser to prevent palmitoylation and thus plasma membrane localization of the chimeras. The numbering used refers to Rab6 amino acids; for the homologous amino acid in Ras, subtract 11 from the Rab6 residue number (see text). All of the chimeras have an N-terminal Myc tag. Golgi complex localization was investigated by immunofluorescent staining using the anti-Myc antibody 9E10. All of the localization data are summarized here, and selected confocal images are shown in Fig. 8. +++, wild-type Golgi complex staining; +, weak Golgi complex staining (as seen in Fig. 6c). (B) The Rab-L2 Ras, Rab-L3Ras, and Rab-L2+L3Ras proteins have CXC C-terminal motifs and are processed to the same extent as wild-type Rab6 in COS cells (not shown). COS cells expressing these proteins were fractionated into S100 (s) and P100 (p) fractions, and equal proportions of all fractions resolved by SDS-PAGE and immunoblotted with the anti-Myc antibody 9E10. All of these chimeras are extensively membrane bound.

subcellular localization of the Rab155-Ras chimera was critically dependent on the specific C-terminal lipid modification. A palmitic acid moiety with either a farnesyl or geranylgeranyl isoprenoid localized the Rab155-Ras protein both to the plasma membrane and to the Golgi complex. This finding illustrates the critical role of palmitic acid in targeting proteins to the plasma membrane, which has already been demonstrated for Ras and certain heterologous proteins (25, 34). However, the plasma membrane-targeting effect of palmitic acid was overcome in presence of the C-terminal hypervariable domain of Rab6, since palmitoylated and farnesylated, as well as palmitoylated and geranylgeranylated, forms of Rab6 were found exclusively in the Golgi complex. One explanation for this finding is that the hypervariable domain of Rab6 may enhance the avidity of Golgi complex association by stabilizing the interaction of the $\mathbf{N}$ terminus with a Golgi complex receptor protein. The immunofluorescence data are consistent with this view because the Golgi complex staining observed with the nonpalmitoy- lated and geranylgeranylated Rab155-Ras chimera was less intense than that seen with full-length Rab6, suggesting that some P100-associated Rab155-Ras protein was washed out of the cells prior to fixation. Alternatively, the hypervariable domain of Rab6 may interact with proteins that are not directly concerned with subcellular targeting but can indirectly prevent a C-terminal palmitoyl group binding to plasma membrane.

The sequence in N-terminal 155 amino acids of Rab6 that is required for Golgi complex localization mapped to the effector domain. If the effector domain of Rab6 is required for binding to Rab6-GAP, as is the case with Ras, there is the interesting possibility that the Golgi complex docking protein for Rab6 is Rab6-GAP itself. This predicts that Rab6GAP should colocalize with Rab6 to the Golgi. Recently, Gyp6p, a specific GAP for Ypt6p, the yeast homolog of Rab6, has been cloned (47a), but the subcellular localization of Gyp6p has not been reported. It could be argued that the Rab-L2Ras chimeras mislocalize because they are fixed in 

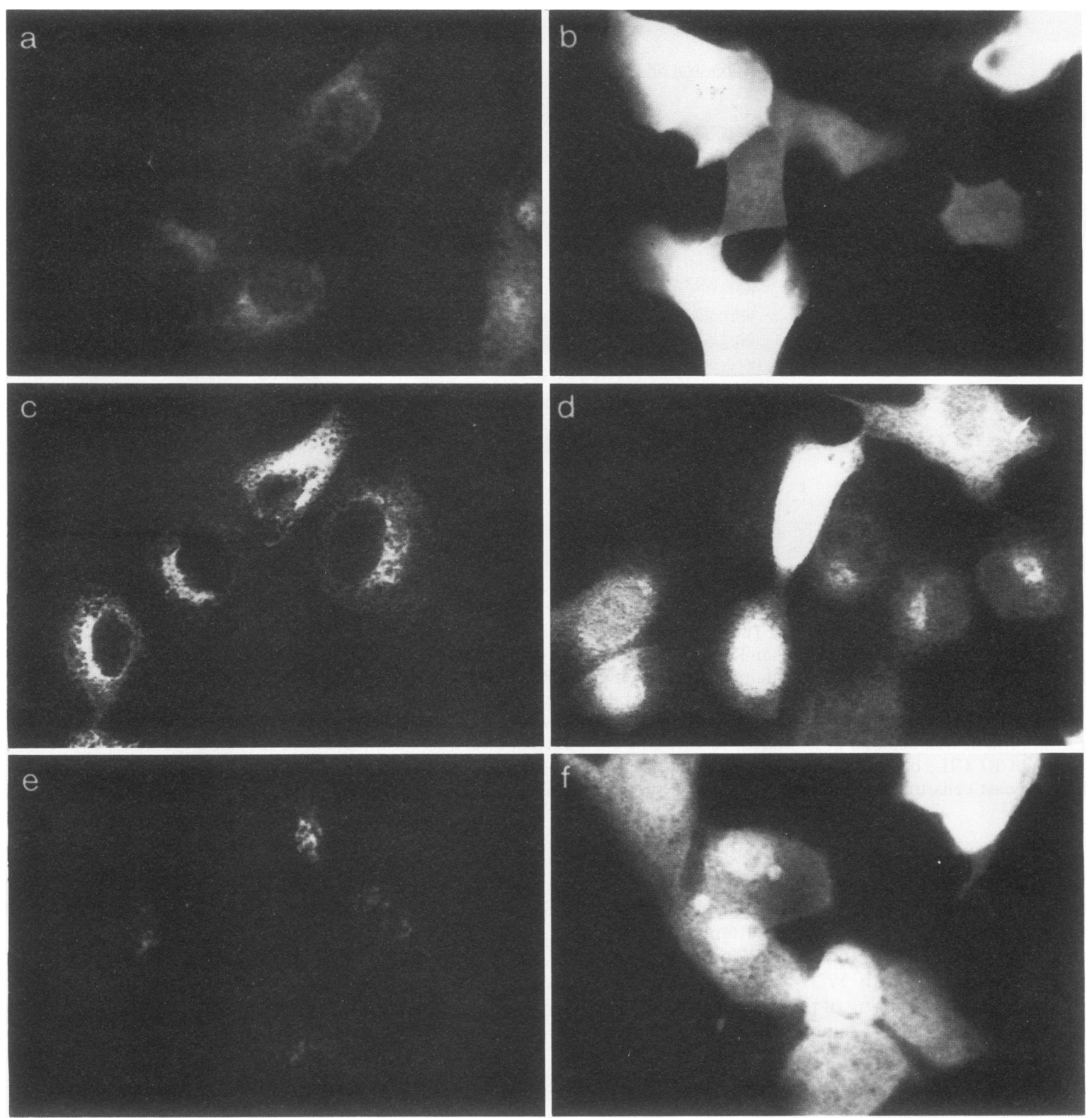

FIG. 8. MDCK cells were microinjected with Rab-L2Ras (a and b), Rab-L3Ras (c and d), or Rab-L2+L3 (e and f) plasmids and examined $18 \mathrm{~h}$ later. The cells in panels a, c, and e were permeabilized and washed before fixation. The Rab-L3 chimera (c) shows wild-type Golgi complex staining, while both of the chimeras with the effector domain of Ras substituting for the Rab6 effector domain show barely detectable Golgi staining. Panels $b, d$, and $f$ show cells fixed before permeabilization and washing to verify that the level of expression of each of these chimeras in MDCK cells was similar. All staining was carried out with the anti-Myc antibody 9E10.

the GTP-bound form as a result of not interacting with Rab6-GAP. However, we do not think that this is likely because Rab6 which is constitutively GTP bound as a result of a G23V substitution is localized normally to the Golgi (21a). We attempted to target Ras to the Golgi complex by replacing homologous Ras sequences with the effector and hypervariable domains of Rab6 together with a CCIL motif. Unfortunately, this chimera was unstable. Thus, while we have shown that the effector domain of Rab6 is essential for localization and that the hypervariable domain enhances Golgi complex association, we cannot conclude that these sequences are fully sufficient for localization.

Our data on Rab6 show that the subcellular targeting of
Rab proteins is more complex than previously thought, since in addition to lipid modifications, both $\mathrm{N}$-terminal and $\mathrm{C}$-terminal domains appear to be involved. These data may also be of relevance to another Ras-related protein, Rap1, which is localized in the Golgi complex (4). This protein possesses a $\mathrm{C}$ terminus with a CAAL box and a polylysine domain which can target heterologous proteins to the plasma membrane (25), suggesting that the Golgi complex localization of Rap1 involves other domain(s) which override the C-terminal plasma membrane-targeting motif.

We also addressed whether, in addition to their role in membrane binding, lipid-modifying groups and C-terminal sequences were important for the biological activity of Rab6. 
A

Rab6 Protein Expressed
None
Rab6 (wild-type)
RabCC
RabCKCCIL
RabCCIL
None
Rab6 (wild-type)
Rab155Ras
RabCKCVLS
RabCVLS

C
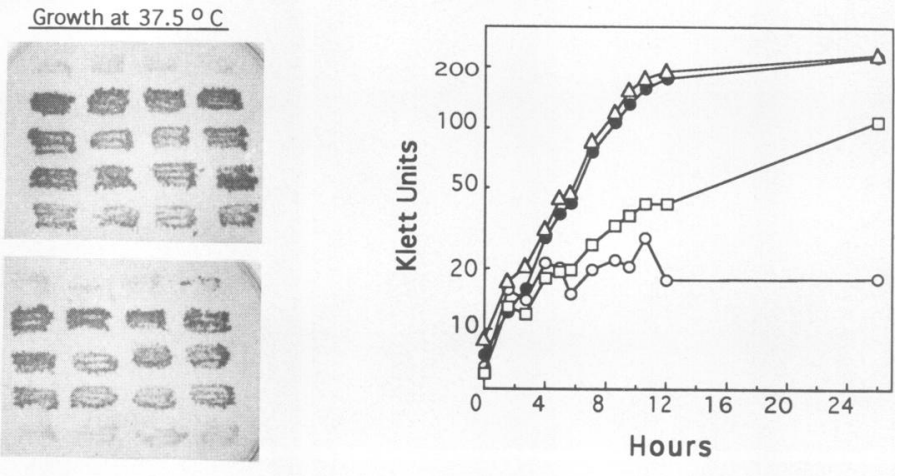

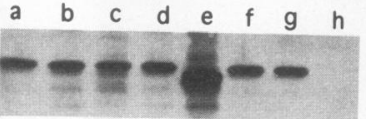

FIG. 9. (A) Replica-plating assay of growth at high temperature of yeast cells containing a mutation in the Rab6 homolog (ypt6::LEU2) and plasmids which express wild-type or mutant Rab6 C-terminal mutant proteins. The Rab6 C-terminal mutants are described in Table 1 , and the Rab-Ras construct is chimera a in Fig. 4. The ypt6::LEU2 mutation blocks growth at $37.5^{\circ} \mathrm{C}$ when the cells are grown in synthetic medium and is suppressed by expression of mammalian Rab6 and all of the C-terminal mutants of Rab6 except RabCVLS. (B) Growth in liquid cultures following a shift to $37.5^{\circ} \mathrm{C}$ of yeast cells containing a mutation in the Rab6 homolog (ypt6::LEU2) and plasmids which express no gene (open circles), wild-type Rab6 (closed circles), or Rab6 C-terminal mutant protein RabCC (open triangles) or RabCCIL (open squares). (C) Yeast cells transformed by each of the Rab6 mutant and wild-type plasmids were grown at the permissive temperature. Lysates were prepared, and $40 \mu \mathrm{g}$ of total protein was acetone precipitated, resolved by SDS-PAGE, and Western blotted with the anti-Myc antibody 9E10. Lanes: a, RabCC; b, RabCKCCIL; c, RabCCIL; d, RabCKCVLS; e, Rab155-Ras (with a CKCVLS C terminus); f, Rab6 wild-type C terminus; g, RabCVLS; h, yeast cells transformed with an empty vector.

To this end, we used $S$. cerevisiae as a model system since it contains a gene, YPT6, which is highly homologous to rab6 $(31,47 a)$. We found that the ability of mutant Rab6 proteins to functionally complement the growth defect at higher temperatures associated with YPT6 deletion correlates directly with the correct targeting of these proteins to the Golgi complex in mammalian cells. Thus, in this assay, farnesylation alone as a C-terminal lipid modification is unable to render the Rab6 protein biologically active. This is the first in vivo demonstration of the relevance of specific prenoid modification to Rab function and also highlights the importance of localization to Rab function. Interestingly, the correlation between correction of temperature-sensitive phenotype and Golgi complex localization extended to the Rab-Ras chimeric proteins which lack the hypervariable domain of Rab6. These data indicate that at least in yeast cells, the hypervariable domain of Rab6 is not required for biological activity. A subtle difference was observed between the methylated RabCCIL and nonmethylated RabCC proteins that were prenylated with a single geranylgeranyl group. While both of these mutant Rab6 proteins localized normally in the Golgi complex and both corrected the temperature-sensitive growth defect in $S$. cerevisiae, it was clear that yeast cells expressing the methylated protein grew significantly more slowly than those expressing the nonmethylated protein. It is possible that the interaction of Rab6 with a protein essential for biological activity but not for Golgi complex localization may be favored by a negatively charged $\mathrm{C}$ terminus in the context of a single geranylgeranyl group. It is worth noting that Rho and Rac proteins that are geranylgeranylated, AAX proteolysed, but nonmethylated after processing in the presence of an inhibitor of methyltransferase bind more extensively to RhoGDI than the fully processed methylated proteins do (27). We are currently investigating to what extent the mutant Rab6 proteins described here interact with RabGDI, a protein which functions in the recycling of Rab proteins between donor and acceptor membranes (3).

Taken together, our results describe the respective roles of posttranslational modifications and targeting sequences in the subcellular localization and biological function of a Rab protein. The mechanisms that lead to the preferential association of Rab proteins with specific membranes and the identification of the components with which they interact remain to be unravelled.

\section{ACKNOWLEDGMENTS}

This work was supported in part by grants to J.G. and F.B. from the Association pour la Recherche contre la Cancer, France, and the Association Claude Bernard, France. Work in the Chester Beatty Laboratories is supported by the Medical Research Council and the Cancer Research Campaign. We thank Dieter Gallwitz for providing the GL72 yeast strain and for discussing his results prior to publication, Tony Magee for help with the isoprenoid analysis, Bruno Goud for anti-Rab6 antibodies, Ahmed Zahraoui for the Rab6 cDNA, Armand Tavitian for support, and Karen Cadwallader for assistance.

\section{REFERENCES}

1. Adamson, P., C. J. Marshall, A. Hall, and P. A. Tilbrook. 1992. Posttranslational modifications of rho proteins. J. Biol. Chem. 267:20033-20038.

2. Adamson, P., H. F. Paterson, and A. Hall. 1992. Intracellular 
localization of $\mathrm{p} 21^{\text {rho }}$ proteins. J. Cell. Biol. 119:617-627.

3. Araki, S., A. Kikuchi, Y. Hata, M. Isomura, and Y. Takai. 1990. Regulation of reversible binding of $s m g$ p21A, a ras p21-like GTP-binding protein, to synaptic plasma membranes and vesicles by its specific regulatory protein, GDP dissociation inhibitor. J. Biol. Chem. 265:13007-13015.

4. Béranger, F., B. Goud, A. Tavitian, and J. deGunzburg. 1991. Association of the ras-antagonistic rap1/Krev-1 proteins with the Golgi complex. Proc. Natl. Acad. Sci. USA 88:1606-1610.

5. Black, S. D. 1992. Development of hydrophobicity parameters for prenylated proteins. Biochem. Biophys. Res. Commun. 186:1437-1442.

6. Bordier, C. 1981 . Phase separation of integral membrane proteins in Triton X-114. J. Biol. Chem. 256:1604-1607.

7. Bourne, H. R., D. A. Sanders, and F. McCormick. 1990. The GTPase superfamily: a conserved switch for diverse cell functions. Nature (London) 348:125-132.

8. Bourne, H. R., D. A. Sanders, and F. McCormick. 1991. The GTPase superfamily: conserved structure and molecular mechanism. Nature (London) 349:117-127.

9. Bucci, C., R. G. Parton, I. H. Mather, H. Stunnenberg, K. Simons, B. Hoflack, and M. Zerial. 1992. The small GTPase rab5 functions as a regulatory factor in the early endocytic pathway. Cell 70:715-728.

10. Calès, C., J. F. Hancock, C. J. Marshall, and A. Hall. 1988. The cytoplasmic protein GAP is implicated as the target for regulation by the ras gene product. Nature (London) 332:548-551.

11. Casey, P., J. A. Thissen, and J. F. Moomaw. 1991. Enzymatic modification of proteins with a geranylgeranyl isoprenoid. Proc. Natl. Acad. Sci. USA 88:8631-8635.

12. Casey, P. J., P. A. Solski, C. J. Der, and J. E. Buss. 1989. p21ras is modified by a farnesyl isoprenoid. Proc. Natl. Acad. Sci. USA 86:8323-8327.

13. Chardin, P. 1991. Small GTP-binding proteins of the ras family: a conserved functional mechanism? Cancer Cells 3:117-126.

14. Chavrier, P., J.-P. Gorvel, E. Stelzer, K. Simons, J. Gruenberg, and M. Zerial. 1991. Hypervariable C-terminal domain of rab proteins acts as a targeting signal. Nature (London) 353:769772.

15. Chu, G., H. Hoyakawa, and P. Berg. 1987. Electroporation for the efficient transfection of mammalian cells with DNA. Nucleic Acids Res. 15:1311-1326.

16. Clarke, S., J. P. Vogel, R. J. Deschenes, and J. Stock. 1988. Post-translational modification of the $\mathrm{H}$-ras oncogene protein: evidence for a third class of protein carboxyl methyltransferase. Proc. Natl. Acad. Sci. USA 85:4643-4647.

17. Cox, A. D., M. M. Hisaka, J. E. Buss, and C. J. Der. 1992. Specific isoprenoid modification is required for the function of normal but not oncogenic Ras protein. Mol. Cell. Biol. 12:26062615.

18. Farnsworth, C. C., M. Kawata, Y. Yoshida, Y. Takai, M. H. Gelb, and J. A. Glomset. 1991. C terminus of the small GTPbinding protein smg p25A contains two geranylgeranylated cysteine residues and a methyl ester. Proc. Natl. Acad. Sci. USA 88:6196-6200.

19. Fujiyama, A., and F. Tamanoi. 1990. RAS2 protein of Saccharomyces cerevisiae undergoes removal of methionine at $\mathbf{N}$ terminus and removal of three amino acids at $\mathrm{C}$ terminus. $\mathrm{J}$. Biol. Chem. 265:3362-3368.

20. Giannakouros, T., and A. I. Magee. 1993. Protein prenylation and associated modifications. In M. J. Schlesinger (ed.), Lipid modifications of proteins. CRC Press, Inc., Boca Raton, Fla.

21. Gorvel, J. P., P. Chavrier, M. Zerial, and J. Gruenberg. 1991. rab5 controls early endosomes fusion in vitro. Cell 64:915-925.

21a.Goud, B. Personal communication.

22. Goud, B., A. Zahraoui, A. Tavatian, and J. Saraste. 1990. Small GTP-binding protein associated with Golgi cisternae. Nature (London) 345:553-556.

23. Gutierrez, L., A. I. Magee, C. J. Marshall, and J. F. Hancock. 1989. Post-translational processing of $\mathrm{p}^{2} 1^{\text {ras }}$ is two-step and involves carboxyl-methylation and carboxyl-terminal proteolysis. EMBO J. 8:1093-1098.

24. Hall, A. 1990. The cellular functions of small GTP-binding proteins. Science 249:635-640.

25. Hancock, J. F., K. Cadwallader, and C. J. Marshall. 1991. Methylation and proteolysis are essential for efficient membrane binding of prenylated p21K-ras(B). EMBO J. 10:641-646.

26. Hancock, J. F., K. Cadwallader, H. Paterson, and C. Marshall. 1991. A CAAX or a CAAL motif and a second signal are sufficient for plasma membrane targeting of ras proteins. EMBO J. 10:4033-4039.

27. Hancock, J. F., and A. Hall. 1993. A novel role for RhoGDI as inhibitor of GAP proteins. EMBO J. 12:1915-1921.

28. Hancock, J. F., A. I. Magee, J. E. Childs, and C. J. Marshall. 1989. All ras proteins are polyisoprenylated but only some are palmitoylated. Cell 57:1167-1177.

29. Hancock, J. F., and C. J. Marshall. 1993. Posttranslational processing of Ras proteins. In J. C. Lacal and F. McCormick (ed.), The Ras superfamily of ATPases. CRC Press, Inc. Boca Raton, Fla.

30. Hancock, J. F., H. Paterson, and C. J. Marshall. 1990. A polybasic domain or palmitoylation is required in addition to the CAAX motif to localize p21ras to the plasma membrane. Cell 63:133-139.

31. Hengst, L., H. Wichman, and D. Gallwitz. Ypt6p, a yeast GTP-binding protein involved in vacuolar protein sorting. Submitted for publication.

32. Horiuchi, H., M. Kawata, M. Katayama, Y. Yoshida, T. Musha, S. Ando, and Y. Takai. 1991. A novel prenyltransferase for a small GTP-binding protein having a C-terminal cys-ala-cys structure. J. Biol. Chem. 266:16981-16984.

33. Hrycyna, C., and S. Clarke. 1992. Maturation of isoprenylated proteins in Saccharomyces cerevisiae. J. Biol. Chem. 267: 10457-10464.

34. Huang, D. C. S., C. J. Marshall, and J. F. Hancock. 1993. Plasma membrane targeted RasGAP is a potent suppressor of p21 ras function. Mol. Cell. Biol. 13:2420-2431.

35. Khoshavi-Far, R., G. J. Clark, K. Abe, A. D. Cox, T. McLain, R. J. Lutz, M. Sinensky, and C. J. Der. 1992. Ras(CXXX) and Rab (CC/CXC) prenylation signal sequences are unique and functionally distinct. J. Biol. Chem. 267:24363-24368.

36. Khosravi-Far, R., R. J. Lutz, A. D. Cox, L. Conroy, J. R. Bourne, M. Sinensky, W. E. Balch, J. E. Buss, and C. J. Der. 1991. Isoprenoid modification of rab proteins terminating in CC or CXC motifs. Proc. Natl. Acad. Sci. USA 88:6264-6268.

37. Kinsella, B. T., R. A. Erdman, and W. A. Maltese. 1991. Carboxyl-terminal isoprenylation of ras-related GTP-binding proteins encoded by rac1, rac2 and ralA. J. Biol. Chem. 266:9786-9794.

38. Kinsella, B. T., and W. A. Maltese. 1991. Rab GTP binding proteins implicated in vesicular transport are isoprenylated in vitro within a novel carboxy-terminal motif. J. Biol. Chem. 266:8540-8544.

38a.Klausner, R. D., J. G. Donaldson, and J. Lippincott-Scwartz. 1992. Brefeldin A: insights into the control of membrane traffic and organelle structure. J. Cell Biol. 116:1071-1080.

39. Magee, A. I., L. Gutierrez, I. A. McKay, C. J. Marshall, and A. Hall. 1987. Dynamic fatty acylation of $\mathrm{p} 21^{N-\text { ras }}$. EMBO J. 6:3353-3357.

40. Molenaar, C. M. T., R. Prange, and D. Gallwitz. 1988. A carboxyl-terminal cysteine residue is required for palmitic acid binding and biological activity of the ras-related yeast YPT1 protein. EMBO J. 7:971-976.

41. Moores, S. L., M. D. Schaber, S. D. Mosser, E. Rands, M. B. O'Hara, V. M. Garsky, M. S. Marshall, D. L. Pompliano, and J. B. Gibbs. 1991. Sequence dependence of protein isoprenylation. J. Biol. Chem. 266:14603-14610.

42. Newman, C. M., T. Giannakouros, J. F. Hancock, E. H. Fawell, J. Armstrong, and A. I. Magee. 1992. Post-translational processing of Schizosaccharomyces pombe YPT proteins. J. Biol. Chem. 267:11329-11336.

43. Ridley, A. J., and A. Hall. 1992. The small GTP-binding protein rho regulates the assembly of focal adhesions and actin stress fibers in response to growth factors. Cell 70:389-399.

44. Ridley, A. J., H. F. Paterson, C. L. Johnston, D. Diekmann, and A. Hall. 1992. The small GTP-binding protein rac regulates 
growth factor-induced membrane ruffling. Cell 70:401-410.

45. Seabra, M. C., M. S. Brown, C. A. Slaughter, T. C. Sudhof, and J. L. Goldstein. 1992. Purification of component A of Rab geranylgeranyltransferase: possible identity with the choroideremia gene product. Cell 70:1049-1057.

46. Seabra, M. C., J. L. Goldstein, T. C. Sudhof, and M. S. Brown. 1992. Rab geranylgeranyl transferase: a multisubunit enzyme that prenylates GTP-binding proteins terminating in Cys-X-Cys or Cys-Cys. J. Biol. Chem. 267:14497-14503.

47. Seabra, M. C., Y. Reiss, P. J. Casey, M. S. Brown, and J. L. Goldstein. 1991. Protein farnesyltransferase and geranylgeranyltransferase share a common $\alpha$ subunit. Cell 65:429-434.

47a.Strom, M. Vollmer, P., Tan, T. and D. Gallwitz. 1993. A yeast GTPase-activating protein interacts specifically with a membre of the Ypt/Rab family. Nature (London) 361:736-739.

48. van der Sluijs, P., M. Hull, P. Webster, P. Mâle, B. Goud, and I. Mellman. 1992. The small GTP-binding protein rab4 controls an early sorting event on the endocytic pathway. Cell 70:729-740.

49. Walworth, N. C., B. Goud, A. K. Kabcenell, and P. J. Novick. 1989. Mutational analysis of SEC4 suggests a cyclical mechanism for the regulation of vesicular traffic. EMBO J. 8:16851693.

50. Wei, C., R. Lutz, M. Sinensky, and I. G. Macara. 1992. p23 $3^{\mathrm{rab} 2}$, a Ras-like GTPase with a -GGGCC C-terminus, is isoprenylated but not detectably carboxylmethylated in NIH3T3 cells. Oncogene 7:467-473.

51. Willumsen, B. M., A. Christensen, N. L. Hubbert, A. G. Papageorge, and D. R. Lowy. 1984. The p21 ras C-terminus is required for transformation and membrane association. Nature (London) 310:583-586.

52. Zahraoui, A., N. Touchot, P. Chardin, and A. Tavitian. 1989. The human rab genes encode a family of GTP-binding proteins related to yeast YPT1 and SEC4 products involved in secretion. J. Biol. Chem. 264:12394-12401. 